archives

of thermodynamics

Vol. 37(2016), No. 2, 3-22

DOI: $10.1515 /$ aoter-2016-0010

\title{
Statistical analysis of entropy generation in longitudinally finned tube heat exchanger with shell side nanofluid by a single phase approach
}

\author{
PAVAN KUMAR KONCHADA* \\ VINAY PV \\ VARAPRASAD BHEMUNI
}

Department of Mechanical Engineering, GVP College for Degree and PG Courses (Technical Campus), Rushikonda, Visakhapatnam, A.P., India

\begin{abstract}
The presence of nanoparticles in heat exchangers ascertained increment in heat transfer. The present work focuses on heat transfer in a longitudinal finned tube heat exchanger. Experimentation is done on longitudinal finned tube heat exchanger with pure water as working fluid and the outcome is compared numerically using computational fluid dynamics (CFD) package based on finite volume method for different flow rates. Further $0.8 \%$ volume fraction of aluminum oxide $\left(\mathrm{Al}_{2} \mathrm{O}_{3}\right)$ nanofluid is considered on shell side. The simulated nanofluid analysis has been carried out using single phase approach in CFD by updating the user-defined functions and expressions with thermophysical properties of the selected nanofluid. These results are thereafter compared against the results obtained for pure water as shell side fluid. Entropy generated due to heat transfer and fluid flow is calculated for the nanofluid. Analysis of entropy generation is carried out using the Taguchi technique. Analysis of variance (ANOVA) results show that the inlet temperature on shell side has more pronounced effect on entropy generation.
\end{abstract}

Keywords: Longitudinal finned tube heat exchanger; User functions and CEL Expressions; ANSYS CFX; Taguchi; Entropy generation

\footnotetext{
${ }^{*}$ Corresponding Author. E-mail: pavankonchada@gmail.com
} 


\section{Nomenclature}

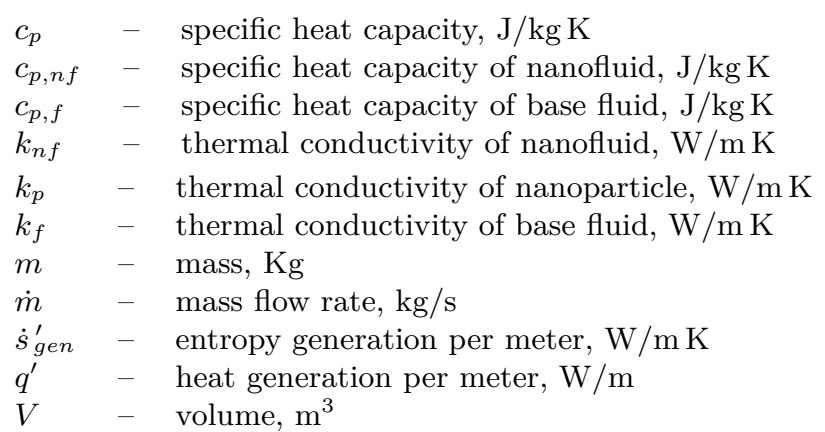

\section{Greek symbols}

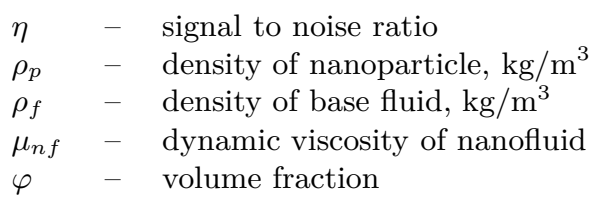

\section{Subscripts}

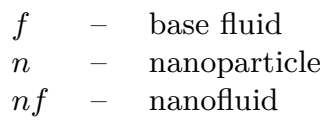

\section{Introduction}

In present day vigorous research has been going on in the field of nanotechnology. Nanoparticles mixed in the base fluids are showing great augmentation of heat transfer characteristics. These nanoparticles have a large surface area per unit mass compared to large particles and thereby when added to a fluid, they admirably enhance the thermophysical properties of the fluid. Promising results of nanofluids have been reported in the literature over conventional fluids for heat transfer in industrial applications. The immense literature available to this day, one can easily evaluate the properties of a nanofluid treating it as a single phase fluid. This approach was affirmed by several numerical investigations carried out in finding the difference between the properties of a nanofluid by treating it as a single phase fluid against two phase fluid. Entropy generated due to heat transfer and fluid friction is another field to contemplate in order to reduce the irreversibility's.

Thermal and hydraulic performance were carried on a car radiator for 
water and ethylene glycol based nanofluids [1]. Lee et al. [2] has found that thermal conductivity is observed for water and ethylene glycol based $\mathrm{CuO}$ and $\mathrm{Al}_{2} \mathrm{O}_{3}$ nanofluids compared to that of the base fluids. Naraki et al. [3] and Peyghambarzadeh et al. [4] studied the behavior of $\mathrm{CuO}$ nanoparticles in laminar flow. Wang et al. [5] has observed that thermal conductivity and heat transfer was enhanced due to increase in concentration. Similar observation was noticed with the works of Eastman et al. [6] in thermal conductivity compared to the corresponding base fluids for $5 \% \mathrm{~V} / \mathrm{V}$ of nanoparticle concentration by $60 \%$. Wang et al. [7] in his work observed that the usage of $3 \%$ volume concentration of nanoparticles augmented effective thermal conductivity by $12 \%$ whereas Masuda et al. [8] reported $20 \%$ augmentation in thermal conductivity for same concentration. From different investigation it is observed that single phase approach is appropriate for $\mathrm{Al}_{2} \mathrm{O}_{3}$ and $\mathrm{TiO}_{2}$ nanofluids. Keshavarz et al. [9] modeled the fully developed laminar flow of nanofluids in computational fluid dynamic (CFD) by assuming constant heat flux and unconcealed heat transfer dependence on concentration of nanofluid. The results of simulation showcased nearly $10 \%$ variation from experimental results at concentrations of $1 \%, 2 \%$, and $4 \%$ for different particle diameters and reaffirmed that heat transfer augments with the increase in concentration of nanoparticles. Demir et al. [10] concluded that heat transfer is augmented by the nanoparticles. Das et al. [11] has noticed aluminum oxide $\left(\mathrm{Al}_{2} \mathrm{O}_{3}\right)$ up to a concentration of $4 \%$ behaves as Newtonian fluid. It is noticed that not much work has been done towards numerical study of nanofluid to optimize its coolant behavior in a heat exchanger. Statistical analysis is carried out on carbon nanotube coated fin by Senthilkumar et al. [12] and it is observed that temperature data obtained from experiment and statistics were in close agreement. Singh et.al., have investigated and confirmed that fluid irreversibility are more in pipes of lower diameter compared to thermal irreversibility [13]. The entropy increment as a measure of energy degradation in heat transfer realized in typical surface heat exchangers so entropy helps in evaluating the performance of heat exchangers [14].

The objective of the present work is to compare experimental results against numerical data collected at experimental rig. The numerical model represents longitudinal finned tube heat exchanger with water on both the tube and shell side. The same model is used for simulation with nanofluid on the shell side and water in the tube. Further, the parameters more responsible for reducing the entropy generated in the tube side is carried out 
using the analysis of variance (ANOVA). Taguchi's technique is chosen to predict the most competent way of reducing entropy generation through a given set of experiments.

\section{Experimental setup and procedure}

To facilitate the experimentation, a longitudinal finned tube heat exchanger as shown in Fig. 1 is fabricated with dual flow loops. The tube side fluid, flows within a copper tube of length $657 \mathrm{~mm}$, diameter of $16 \mathrm{~mm}$ and thickness of $1.5 \mathrm{~mm}$. To this tube, 8 longitudinal fins are brazed. Each fin has a height of $12.5 \mathrm{~mm}$ and a thickness of $2 \mathrm{~mm}$. The entire assembly of tube and its brazed fins are placed inside a shell having an outer diameter of $60 \mathrm{~mm}$ and wall thickness of $1.5 \mathrm{~mm}$. Shell side is well insulated with insulation material so that there is no heat is released to the surroundings. Counter flow is considered for better effectiveness. Thermocouples are installed at all the four terminals and provisions are made to measure the flow rate of tube side and shell side fluid.

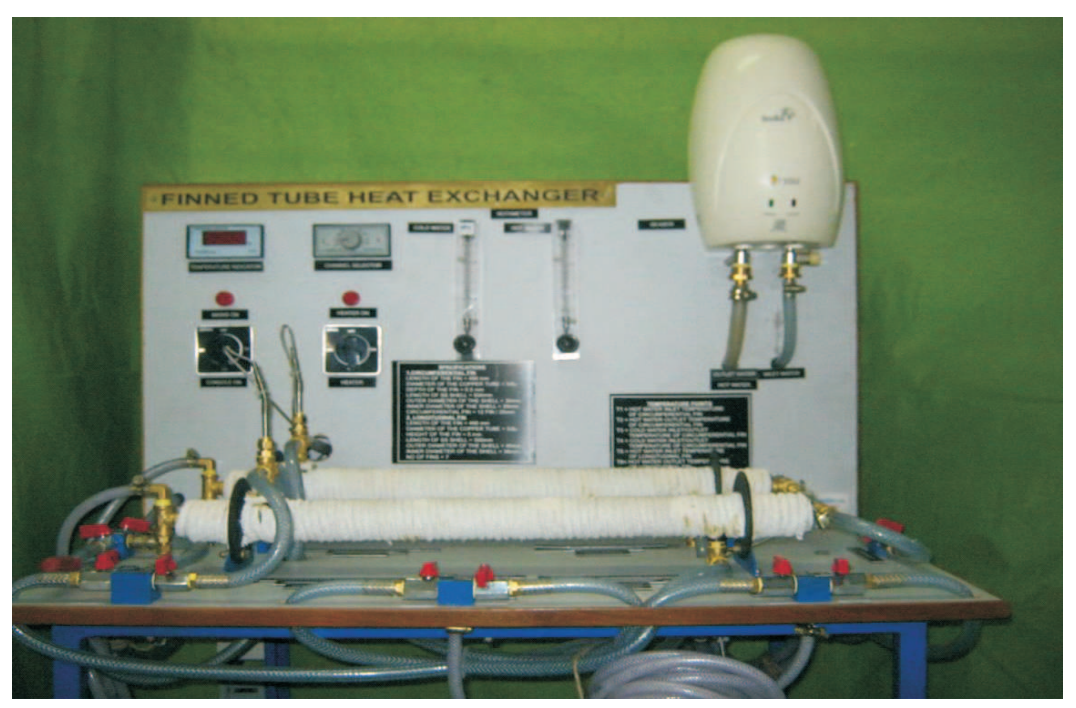

Figure 1: Experimental setup of longitudinal finned tube heat exchanger. 


\section{CFD methodology and entropy generation}

\subsection{Mathematical model}

The governing differential equation 'continuity equation' derived from conservation of mass principle, the 'momentum or Navier-Stokes equation' derived from conservation of momentum principle and the 'energy equation' derived from conservation of energy principle were the three conservation principles used in development of the mathematical model. These fundamental equations along with appropriate initial conditions and boundary conditions were solved to understand various fluid and heat flow characteristics prevailing in the heat exchanger. Finite volume method is employed by using first order upwind scheme. The continuity equation given for steady state flow of a compressible fluid is

$$
\frac{\partial\left(\rho U_{i}\right)}{\partial x_{i}}=0
$$

where $\rho$ is the density of the fluid, $U_{i}$ is the velocities in three directions of $\mathrm{x}, \mathrm{y}, \mathrm{z}$ as pointed by $i=1,2,3$. The momentum equation given for steady state flow of a compressible fluid is

$$
U_{j} \frac{\partial\left(\rho U_{i}\right)}{\partial x_{j}}=-\frac{\partial P}{\partial x_{i}}+\frac{\partial}{\partial x_{j}}\left[\left(\mu+\mu_{T}\right) \frac{\partial\left(\rho U_{i}\right)}{\partial x_{j}}\right],
$$

where $P$ is the pressure, $\mu$ and $\mu_{T}$ are the dynamic and turbulent viscosity, respectively, $(i, j=1,2,3)$. The energy equation given for steady state flow of a compressible fluid is

$$
c_{p} U_{j} \frac{\partial(\rho T)}{\partial x_{j}}=\frac{\partial}{\partial x_{j}}\left[\left(k+k_{T}\right) \frac{\partial(\rho T)}{\partial x_{j}}\right],
$$

where $T$ is the temperature, $c_{p}$ is the specific heat capacity, $k$ and $k_{T}$ are the thermal and turbulent conductivity, respectively, $j=1,2,3$.

Numerically these equations are solved with appropriate turbulence model. The $k-\varepsilon$ turbulence model, from linear eddy viscosity models, proposed by Launder and Spalding [15], is used in several linear and nonlinear eddy viscosity models. Easy convergence, good accuracy with reduced numerical efforts made the model an apt one [16]. It is a two equation model with $k$ indicating the turbulence kinetic energy and $\varepsilon$ indicating the turbulence eddy dissipation. 
For dimensional homogeneity, turbulent viscosity, $\mu_{T}$, may be expressed as $[17]$

$$
\mu_{T}=C_{\mu}^{\prime} \rho k^{\frac{1}{2}} l_{s},
$$

where $C_{\mu}^{\prime}$ is a constant at high Reynolds numbers and $l_{s}$ is the length scale calculated by using the trace of volumetric rate of dissipation of kinetic energy, $\varepsilon$. At high Reynolds numbers $\varepsilon$ may be assumed to be proportional to $k^{\frac{3}{2}} / l_{s}[17]$.

\subsection{Solution procedure}

The governing equations (1)-(3) (continuity, momentum and energy equations) are solved using commercial computational fluid dynamics software ANSYS CFX 15 along with the following assumptions:

1. Steady state conditions are assumed for the flow of water within the tube and around the tube (shell side flow).

2. Fluids is considered in single phase with equivalent thermophysical properties of a two phase fluid (nanoparticles in base fluid).

3. Outer tube of longitudinal finned tube heat exchanger is assumed to be well insulated and thereby it is treated as an adiabatic wall.

4. The material of fins and inner tube (copper) is assumed to have an isotropic nature.

5. The most common in CFD $k-\varepsilon$ turbulence model is considered for simulation in order to reap the benefits of having reasonable accuracy and fast convergence competency with decreased numerical effort.

\subsection{Modeling}

A multiplatform computer-aiding design (CAD) modeling software CATIA V5R20 (computer aided three-dimensional interactive application) was used for preparing the model of longitudinally finned tube heat exchanger. In order that the CAD model replicates the experimentation dimensions of the heat exchanger adequate care is taken and the model as shown in Fig. 2 is considered. 


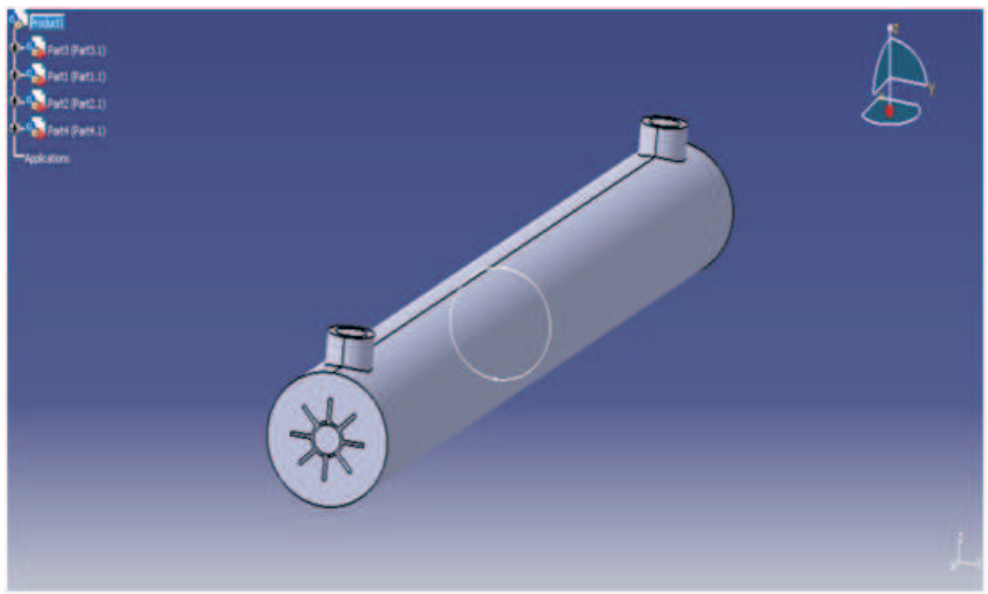

Figure 2: Modeling of longitudinally finned tube heat exchanger and fluid made in CAD.

\subsection{Mesh topology}

Four zones ( 2 fluids and 2 solids) are selected to form a new part in design modeler so that interfaces will be automatically created as shown in Fig. 3. Meshing was done in ANSYS ICEM CFD software package for mesh generation with following preferences as shown in Tab. 1.

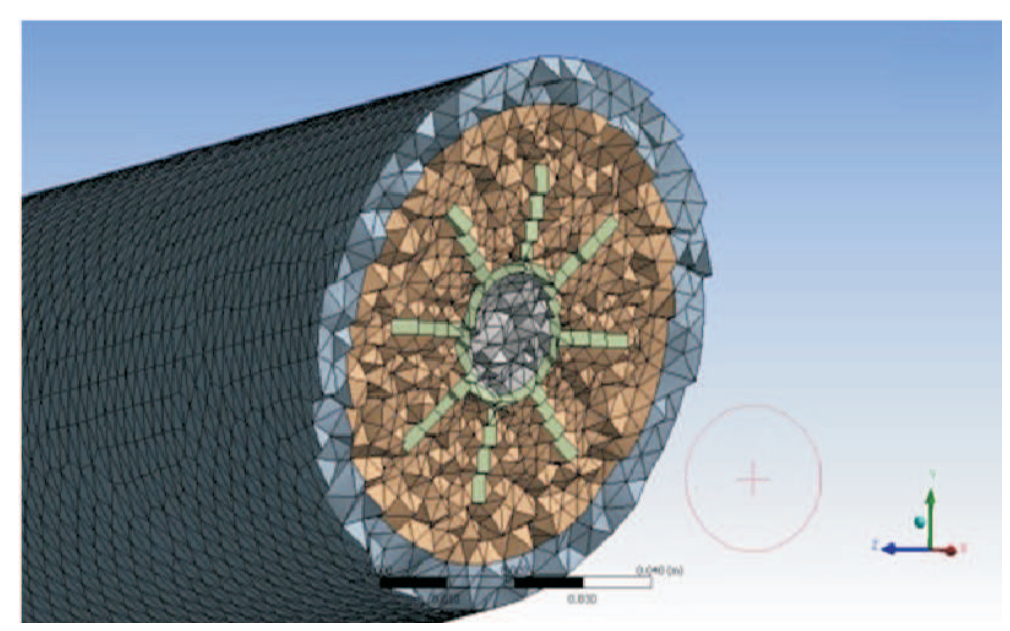

Figure 3: Cut section mesh of longitudinally finned tube heat exchanger. 
Table 1: Preferences selected for meshing the model.

\begin{tabular}{|l|c|}
\hline Reference & CFD \\
\hline \hline Solver reference & CFX \\
\hline Release no. & 15 \\
\hline Advanced size function & curvature on \\
\hline Relevance centre & fine \\
\hline Smoothing & high \\
\hline Transition & slow \\
\hline Span angle center & fine \\
\hline Growth rate & 1.2 \\
\hline
\end{tabular}

In order to investigate the best suited mesh density, analysis was repeated for several mesh densities and the propinquity of results were observed for all these mesh densities. It was observed thatthe mesh independent solution is obtained for nodes $9,28,315$ and elements $28,254,561$.

\subsection{Thermophysical properties of nanofluid}

Density of nanofluids at different concentrations was proposed by Cho [18] and compared with the 'digital density meter' readings and concluded that the equation proposed can be used for finding the density of a nanofluid and is given as

$$
\rho_{n f}=\varphi \rho_{p}+(1-\varphi) \rho_{f},
$$

where $\rho_{p}$ and $\rho_{f}$ refer to the density of nanoparticle and base fluid, respectively, and $\varphi$ denotes the volume fraction.

Koo and Kleinstreuer [19] proposed correlations with the consideration of Brownian motion, which have been used for calculating the thermal conductivity of nanofluids, $k_{n f}$, in the present study

$$
\begin{aligned}
k_{n f} & =k_{f}+3 \varphi \frac{k_{p}-k_{f}}{2 k_{f}+k_{p}-\varphi\left(k_{p}-k_{f}\right)} k_{f}+5 \times 10^{4} \beta \rho_{f} C_{f} \varphi \\
& \times \sqrt{\frac{k_{b} T}{2 \rho_{p} r_{p}}[(-134.63+1722.3 \varphi)+(0.4705-6.04 \varphi) T]},
\end{aligned}
$$

where $T$ is the temperature and $r_{p}$ is the radius of the nanoparticle.

The parameter $\beta$ is related to the nanoparticle Brownian motion and 
was determined empirically as [19]

$$
\beta= \begin{cases}0.0137(100 \varphi)^{-0.8229} & \text { for } \varphi<0.01, \\ 0.0011(100 \varphi)^{-0.7272} & \text { for } \varphi>0.01 .\end{cases}
$$

The viscosity of the nanofluid was calculated by using Batchelor correlation[20] as very dilute suspensions were used in the present work, hence the dynamic viscosity is given as

$$
\mu_{n f}=\left(1+2.5 \varphi+6.2 \varphi^{2}\right) \mu_{f},
$$

where $\mu_{f}$ is the dynamic viscosity of base fluid. The dynamic viscosity of selected nanofluids is calculated by the Eq. (8) is based on the volume fraction of nanoparticles $\varphi$, and thermal conductivity of the particle $k_{p}$ and base fluid $k_{f}$. The following equation that is applied to calculate the volume concentration of nanoparticles in the base fluid

$$
\varphi=\frac{V_{n}}{V_{n}+V_{f}}=\frac{\frac{m_{n}}{\rho_{n}}}{\frac{m_{n}}{\rho_{n}}+\frac{m_{f}}{\rho_{f}}},
$$

where $V$ is the volume, $m$ is the mass, $\rho$ is the density, and subscripts $n$ and $f$ refer to nanoparticles and base fluid, respectively.

Differential scanning calorimetry is generally used to estimate the specific heat capacity. In this paper, the correlation given by Xuan and Roetzel [21] was used to facilitate the ease of determining specific heat capacity at various concentrations of the selected nanofluid

$$
C_{p, n f}=\frac{\varphi\left(\rho C_{p}\right)_{n}+(1-\varphi)\left(\rho c_{p}\right)_{f}}{\varphi \rho_{n}+(1-\varphi) \rho_{f}} .
$$

Here as before subscripts $n$ and $f$ refer to nanoparticles and base fluid, again.

Most of the nanofluids manifest near linear increase in thermal conductivity when particle volume concentrations were increased. For water based $\mathrm{Al}_{2} \mathrm{O}_{3}$ nanofluid, at volume concentrations of $0.2,0.75,1.0,1.25,1.5,2.0$, and $3.0 \mathrm{vol} \%$, the augmentation of thermal conductivities when compared to base fluid were observed to be $0.3 \%, 2.0 \%, 2.5 \%, 3.1 \%, 3.7 \%, 4.6 \%$, and $7.4 \%$ respectively. The thermal conductivity values are found to be greater than the values predicted by a classical model like Hamiltone and Crosser model [22]. However, the thermal conductivity values were in near agreement with measured values of Turgut et al. [23] and Yu and Choi [24]. Aluminium oxide nanoparticle properties are shown in Tab. 2. 
Table 2: Properties of $\mathrm{Al}_{2} \mathrm{O}_{3}$ the nanoparticles.

\begin{tabular}{|l|c|r|}
\hline Parameter & Unit & Value \\
\hline \hline$\rho$ & $\mathrm{kg} / \mathrm{m}^{3}$ & 3970 \\
\hline $\mathrm{Cp}$ & $\mathrm{J} / \mathrm{kg} \mathrm{K}$ & 765 \\
\hline $\mathrm{k}$ & $\mathrm{W} / \mathrm{m} \mathrm{K}$ & 36 \\
\hline
\end{tabular}

\subsection{Boundary conditions, solving and post processing}

The solid and fluid domains created in CFX are assigned; on the shell side nanofluid $\left(\mathrm{Al}_{2} \mathrm{O}_{3}+\right.$ water $)$ is considered and plain water on tube side. The effective properties like thermal conductivity, dynamic viscosity, specific heat and density for nanofluid were hooked up by user-defined functions socalled 'user functions' and 'CEL expressions'. Other boundary conditions were

Inlet: Constant temperature with $5 \%$ turbulence is considered for different flow rates;

Outlet: zero gauge pressure is considered (relative to atmospheric pressure);

Wall: Stationary wall with no slip conditions and adiabatic on outer shell side as it is covered with thermal resistant material.

Applied ANSYS CFX solver is a hybrid finite-element/finite-volume discretization solver, consisting of the discrete approximation of the volume and surface integrals of the Navier-Stoke's equations in steady state along with continuity and energy equation, applied to each control volume. Thermophysical properties variability with iterations will be countered by User functions and 'CEL expressions'. The solution is iterated for 6000 to 9000 runs with the convergence criteria of $10^{-6}$. Temperature contours, velocity contours and pressured drop (using mass-avg function) can be viewed in post processing.

\subsection{Entropy generation}

This paper adopts the Bejan's equation and its reduction for different types of fluid flows. For an internal flow with diameter $D$, heat flux $q^{\prime}$, Bejan gave the equation for the rate of entropy generation $[25,26]$ per unit length 
as

$$
\dot{s}_{\text {gen }}^{\prime}=\frac{q^{\prime}}{\pi k T^{2} \times \mathrm{Nu}\left(\operatorname{Re}_{D}, \operatorname{Pr}\right)}+\frac{32 \dot{m}^{3}}{\pi^{2} \rho^{2} T}\left(\frac{f\left(\operatorname{Re}_{D}\right)}{D^{5}}\right),
$$

where $\dot{m}$ and $\rho$ are the mass flow rate and density of the fluid, respectively, $f$ is the friction factor, $\mathrm{Nu}, \mathrm{Pr}$, and $\mathrm{Re}_{D}$ are the Nusselt, Prandtl, and Reynolds numbers, respectively.

As can be seen the total entropy generation rate is contributed by two parts, thermal and fluid friction

$$
\dot{s}_{\text {gen }}^{\prime}=\left(\dot{s}_{\text {gen }}^{\prime}\right)_{\text {Heat Transfer }}+\left(\dot{s}_{\text {gen }}^{\prime}\right)_{\text {Fluid Friction }} \text {. }
$$

Equation (11) also shows the importance of Nusselt number $\mathrm{Nu}$ and friction factor $f$, which are different for different geometry and regime of flow, and so also the overall entropy generation rate.

In the numerical investigation for the given mass flow rate and diameter, Reynolds number is found to be greater than 4000 which means that flow is turbulent. For turbulent flows Dittus-Boelter equation has a form

$$
\mathrm{Nu}\left(\operatorname{Re}_{D}, \operatorname{Pr}\right)=0.023 \operatorname{Re}_{D}^{0.8} \operatorname{Pr}^{0.4},
$$

and Blasius equation for friction factor is given as

$$
f\left(\operatorname{Re}_{D}\right)=0.046 \times \operatorname{Re}_{D}^{-0.2} .
$$

From the above Eqs. (12) and (13) we can rewrite Eq. (10) as

$$
\dot{s}_{\text {gen }}^{\prime}=\frac{q^{\prime}}{\pi k T^{2} \times 0.023 \operatorname{Re}_{D}^{0.8} \operatorname{Pr}^{0.4}}+\frac{32 \dot{m}^{3}}{\pi^{2} \rho^{2} T}\left(\frac{0.046 \times \operatorname{Re}_{D}^{-0.2}}{D^{5}}\right) .
$$

Equation (14) helps in finding the entropy generated for different parameters in internal turbulent flow on the tube side. Heat generation can be obtained from post processing results on tube side and all properties are evaluated at average temperature.

\section{Results and discussion}

Outlet temperature and logarithmic mean temperature difference (LMTD) are the most significant parameters in deciding the performance of heat exchanger. Figures 4 and 5 illustrate the variation of LMTD and temperature with varying hot channel flow rates found from experimentation and CFD 
simulation. Figure 4 shows that both decreases as flow rate enhance. From the trend we can state that the difference between experimental and simulation results for LMTD is utmost $6 \%$. The experimental and simulation difference between hot channel outlet temperatures is of only maximum $2 \%$. So the error percentage obtained from numerical solution by discretization using computational fluid dynamics software to the exact value is within acceptable limit for water as fluid in both shell and tube.

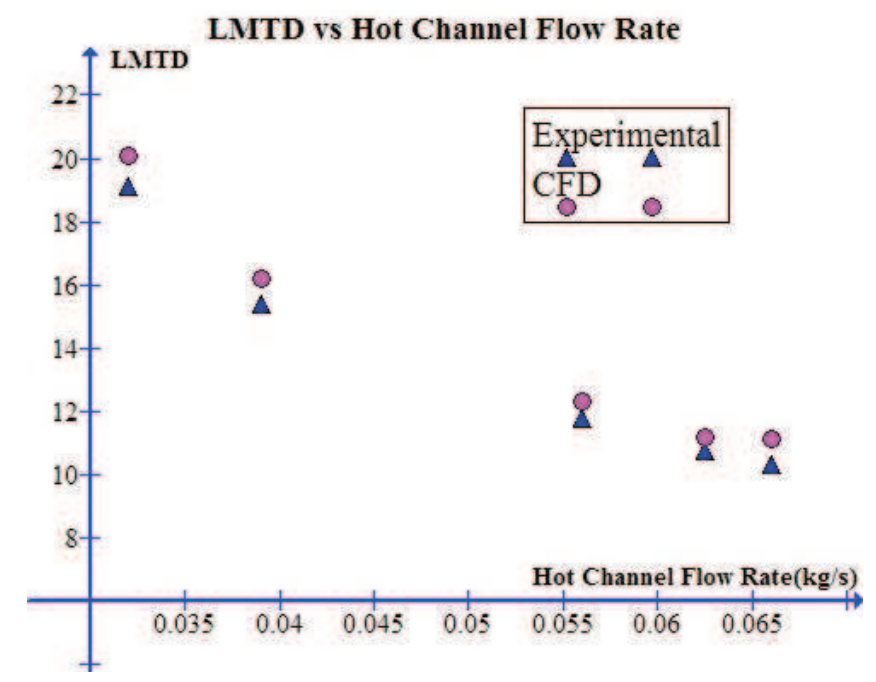

Figure 4: LMTD vs hot channel flow rate graph for both experimental and simulation results.

Volume fraction of $0.8 \% \mathrm{Al}_{2} \mathrm{O}_{3}$ based nanofluid is considered on the shell side for CFD analysis, this percentage is found to yield good results according to Qasim Saleh et. al. [27]. LMTD and outlet temperatures on shell side are investigated in simulation by assuming single phase approach on shell side fluid with and without nanoparticles. Figure 6 shows that LMTD value decreases for the nanofluids compared to fluids without nanoparticles, indicating the augmentation of heat transfer. The outlet temperature shows a decrement as shown in Fig. 7 due to the enhanced heat transfer rate by the addition of nanoparticles.

\subsection{Temperature contours}

At $0.0625 \mathrm{~kg} / \mathrm{s}$ and nanovolume concentration of $0.8 \%$ the temperature contours are shown in Fig. 8. The temperature value is high at inlet and 


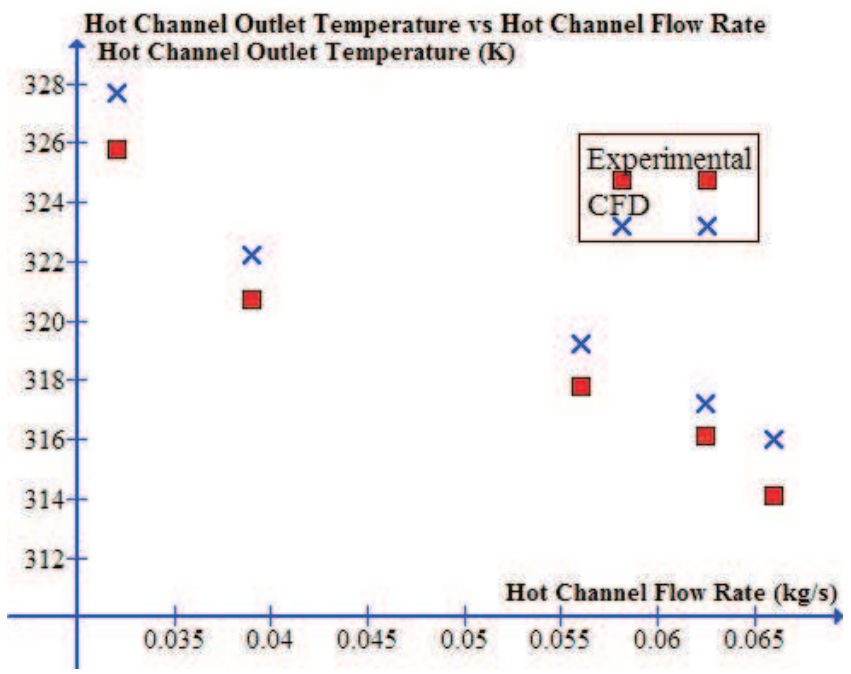

Figure 5: Hot channel outlet temperature vs. hot channel flow rate graph for experimental and simulation results.

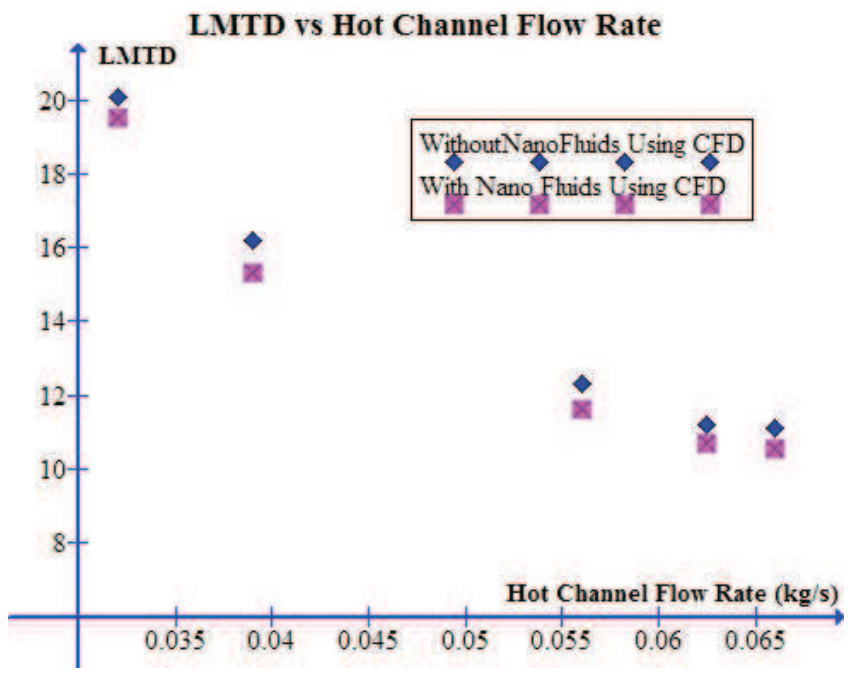

Figure 6: LMTD vs. hot channel flow rate for with and without nanoparticles at $0.8 \%$ volume fraction on the shell side.

decreased along the length of the fin due to heat transfer between shell side nanofluid and tube side of plain fluid by convection. Fins protruding from the tube cause the nanofluid distribution to become uneven making 


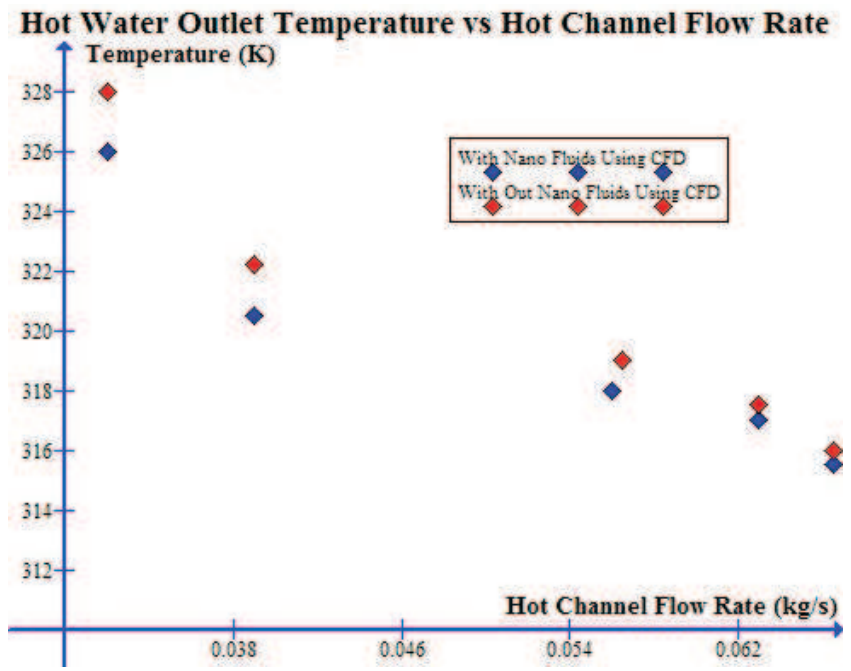

Figure 7: Hot water outlet temperature vs. hot channel flow rate for with and without nanoparticles at $0.8 \%$ volume fraction.

the temperature gradient nonuniform. From the Fig. 8 it can be seen that temperatures on the upper half of shell side fluid is higher than the lower because of the movement of shell side fluid along the longitudinal fins on the surface of the tube.

\subsection{Velocity streamlines and gradient}

It can be perceived from the velocity stream lines contours shown in Fig. 9 that velocity is high on the upper half of shell due to the geometry of the tube. It can be inferred that heat transfer value would be higher on upper side due to high heat transfer coefficient due to augmented convection and turbulence in the flow. The fins on the tube increase the contact surface area and turbulence which serve the purpose of enhancing the heat transfer rate. The increase in the velocity gradient along the fins increases the heat transfer rate and the further the rate is higher at the top of the tube due to the turbulence induced.

\subsection{Taguchi method}

The study to access the impact of process parameters on entropy generation and which parameter has a large impact was analyzed. The process 


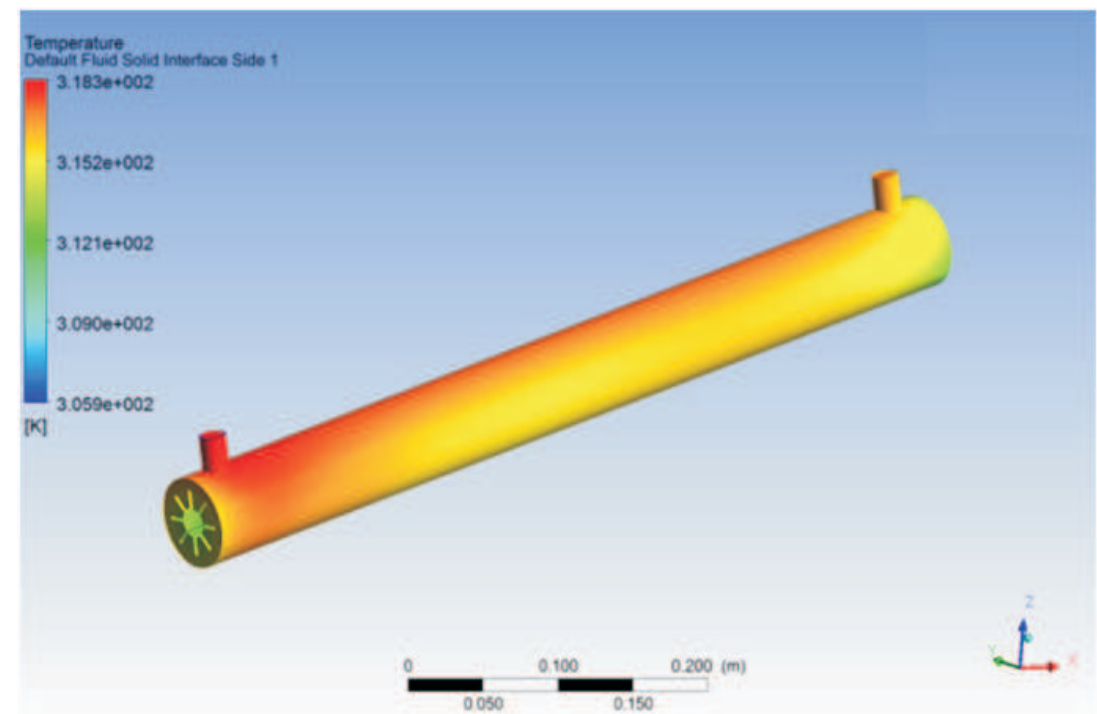

Figure 8: Temperature contours of outer fluid at flow rate of $0.0625 \mathrm{~kg} / \mathrm{s}$ at $0.8 \mathrm{vol} \%$ of nanoparticles.

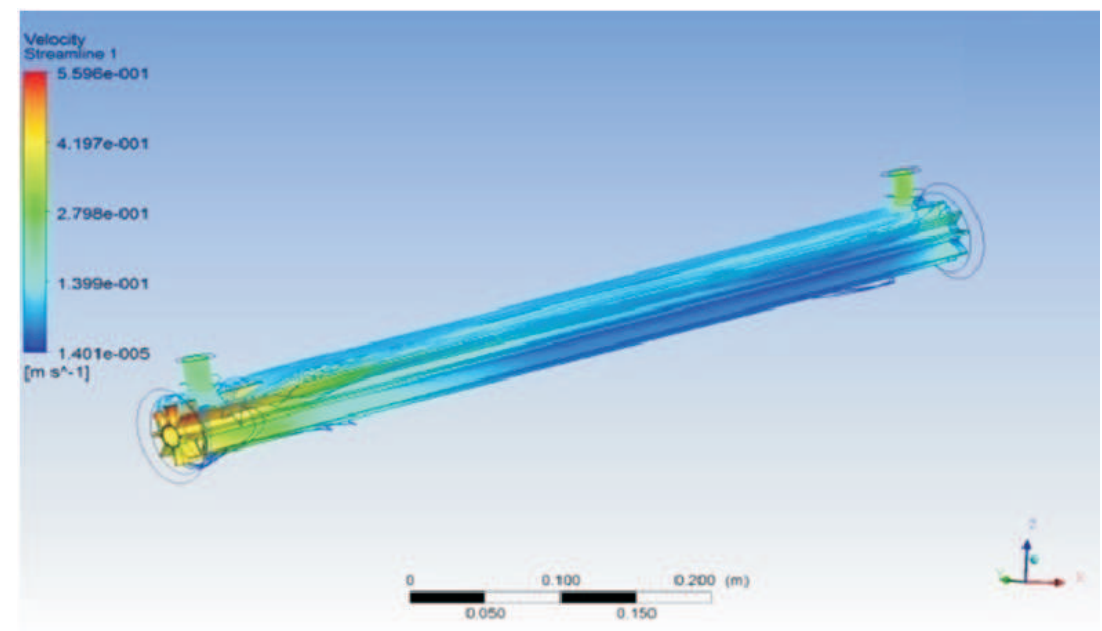

Figure 9: Velocity stream lines above the finned tubes at $0.0625 \mathrm{~kg} / \mathrm{s}$ flow rate with nanoparticles in the fluid.

parameters and their levels as identified are shown in Tab. 3. The design of experiments with analysis of control parameters to obtain best results 
was achieved in the Taguchi method. 'Orthogonal arrays' (OA) provide a set of well balanced (minimum) experiments and their signal-to-noise ratios $(\mathrm{S} / \mathrm{N})$, which are logarithmic functions of desired output. This helps in data analysis and prediction of optimum results. Three levels and two parameters are taken based on Taguchi design of experiments L9 orthogonal array (is used to assess the effect of two independent influencing factors having three levels). These levels are the three independent values to be chosen that are equally spaced having a lower value and a higher value. The experimentation is to be performed at these set of values of the given parameters to assess the output of the experiment.

Table 3: Control factors and levels.

\begin{tabular}{|l|c|c|c|c|}
\hline Control factors & Units & Level 1 & Level 2 & Level 3 \\
\hline \hline Inlet temperature & $\mathrm{K}$ & 311 & 321 & 331 \\
\hline Hot mass flow rate & $\mathrm{kg} / \mathrm{s}$ & 0.03 & 0.04 & 0.05 \\
\hline
\end{tabular}

The analysis was carried out to parameterize the factors that influence the entropy generation of heat exchanger. Hence most crucial factors like temperature of hot fluid, mass flow rate of hot fluid were prudently selected as variables for the numerical analysis to be performed. Table 4 shows L9 orthogonal array the data collected and analysed for various temperatures and mass flow rates.

In the present paper, analysis was carried out to decrease the entropy generation for given flow rates and temperatures. Smaller $\mathrm{S} / \mathrm{N}$ ratios are considered as it is representative of the lesser entropy generated and is computed using equation

$$
\eta=\mathrm{S} / \mathrm{N}=-10 \log _{10} \sum y^{2} / n .
$$

where $y$ is the output and $n$ is the variation observed from the nominal value of the output. The predicted $\mathrm{S} / \mathrm{N}$ ratio $(\eta)$ using the optimal levels of the parameters can be calculated as

$$
\eta=\eta_{m}+\sum_{i=1}^{p} \eta_{i}-\eta_{m},
$$

where $\eta_{m}$ is the total mean of $S / N$ ratio, $\eta_{i}$ is the mean $S / N$ ratio at optimum level and $p$ is the list of main parameters (the list of main parameters are inlet temperature and hot mass flow rate). 
Table 4: L9 orthogonal array data collected for varying temperature and hot mass flow rate.

\begin{tabular}{|c|c|c|c|c|}
\hline $\begin{array}{c}\text { Test } \\
\text { no. }\end{array}$ & $\begin{array}{c}\text { Inlet } \\
\text { temperature } \\
(\mathrm{K})\end{array}$ & $\begin{array}{c}\text { Hot mass } \\
\text { flow rate } \\
(\mathrm{kg} / \mathrm{s})\end{array}$ & $\begin{array}{c}\text { Entropy } \\
\text { generation } \\
(\mathrm{W} / \mathrm{mK})\end{array}$ & $\begin{array}{c}\mathrm{S} / \mathrm{N} \\
\text { ratio }\end{array}$ \\
\hline \hline 1 & 311 & 0.03 & 0.0164 & 35.406 \\
\hline 2 & 311 & 0.04 & 0.0198 & 34.040 \\
\hline 3 & 311 & 0.05 & 0.0231 & 33.024 \\
\hline 4 & 321 & 0.03 & 0.0210 & 33.491 \\
\hline 5 & 321 & 0.04 & 0.0248 & 32.124 \\
\hline 6 & 321 & 0.05 & 0.0280 & 31.108 \\
\hline 7 & 331 & 0.03 & 0.0383 & 28.397 \\
\hline 8 & 331 & 0.04 & 0.0430 & 27.311 \\
\hline 9 & 331 & 0.05 & 0.0463 & 26.314 \\
\hline
\end{tabular}

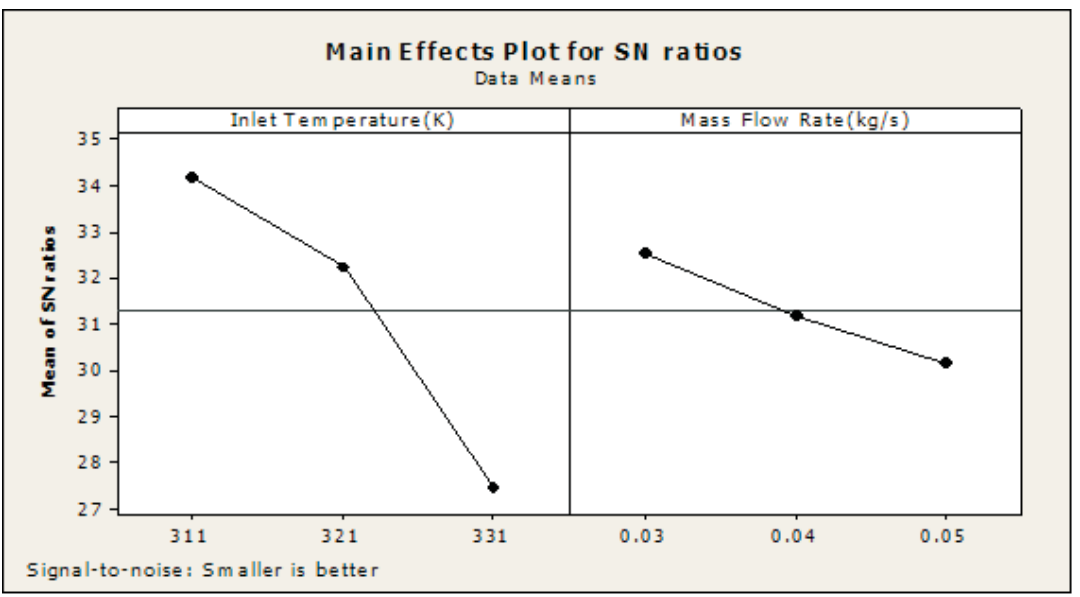

Figure 10: S/N ratio plot showing the entropy generated with temperature and flow rate of shell side fluid.

The values generated from experimentation when compared with the ones obtained from analysis are correlating. The entropy generated at $0.03 \mathrm{~kg} / \mathrm{s}$ mass flow rate and $321 \mathrm{~K}$ inlet temperature of hot fluid is $0.021 \mathrm{~W} / \mathrm{m} \mathrm{K}$. The predicted value for the same mass flow rate and inlet temperature is $0.0208 \mathrm{~W} / \mathrm{m} \mathrm{K}$; this indicates the close propinquity of the analytical and the predicted results. It can be observed from Fig. 10 that, inlet temperature 
of $331 \mathrm{~K}$ and mass flow rate of $0.05 \mathrm{~kg} / \mathrm{s}$ are the set of parameters for lower entropy generation according to the least $\mathrm{S} / \mathrm{N}$ ratio [28] for given fin configuration.

\subsection{Analysis of variance}

The purpose of analysis of variance (ANOVA) is to find the significant factors affecting the entropy generation rate. The P-value for each term tests the null hypothesis that the coefficient is equal to zero (no effect). A low p-value $(<0.05)$ indicates that the null hypothesis can be rejected. In other words, a predictor that has a low p-value is likely to be a meaningful addition to the model because changes in the predictor's value are related to changes in the response variable. $\mathrm{F}$ is the fisher value that gives a similar prediction to the $\mathrm{p}$-value based on fisher tables. R-Sq values have to be higher to ensure that the prediction of the output generated is reasonably good.

Table 5: ANOVA result.

\begin{tabular}{|l|c|c|c|}
\hline Source & Degree of freedom & $\mathrm{F}$ & $\mathrm{P}$ \\
\hline \hline Inlet temperature $(\mathrm{K})$ & 2 & 2708 & 0.000 \\
\hline Hot mass flow rate $(\mathrm{kg} / \mathrm{s})$ & 2 & 257 & 0.05 \\
\hline Error & 4 & & \\
\hline Total & 8 & & \\
\hline
\end{tabular}

$\mathrm{S}=0.000392 \mathrm{R}-\mathrm{Sq}=99.93 \% \mathrm{R}-\mathrm{Sq}(\mathrm{adj})=99.87 \%$

The higher R-Sq (99.93\%) value indicates better fitness of the simulation results to theoretical results. From Tab. 5 it is evident that the ' $\mathrm{P}$ ' value corresponding to the mass flow rate and hot inlet temperature is below 0.05 and thereby from $\mathrm{F}$ index table it is apparent that both the parameters have the influence on entropy generation. It also indicates that inlet temperature has a profound effect due to its low $\mathrm{P}$ value. The analysis using ANOVA confirms the results from obtained analysis.

\section{Conclusions}

Heat transfer rate is augmented compared to base fluid when the shell side fluid is replaced with $0.8 \%$ volume fraction. In the present work experimen- 
tal and numerical analysis of pure water is carried on longitudinally finned tube heat exchanger and then nanofluid is simulated by user-defined functions in numerical investigation. Entropy generation (second law analysis) is carried for the heat exchanger with nanofluid for different flow rates and temperatures using Taguchi method.

$\mathrm{S} / \mathrm{N}$ ratios obtained from Taguchi method show that the inlet temperature of $331 \mathrm{~K}$ and flow rate of $0.05 \mathrm{~kg} / \mathrm{s}$ is the best input pair for a lower entropy generation of $0.021 \mathrm{~W} / \mathrm{mK}$. ANOVA shows that both the factors have a significant effect on entropy generation and temperature has more effect. Furthermore entropy generation analysis can be carried on for varying diameter tubes and concentrations of nanoparticles.

Received 15 December 2015

\section{References}

[1] Peyghambarzadeh S.M., Hashemabadi S.H., Hoseini S.M., Seifi M.: Experimental study of heat transfer enhancement using water/ethylene glycol based nanofluids as a new coolant for car radiators. Int. Comm. Heat Mass Transfer 38(2011), $1283-1290$.

[2] Lee S.S., Choi U.S., Li S.,Eastman J.A.: Measuring thermal conductivity of fluids containing oxide nanoparticles. J. Heat Trans. 121(1999), 2, 280-289.

[3] Naraki M., Peyghambarzadeh S.M., Hashemabadi S.H., Vermahmoudi Y.: Parametric study of overall heat transfer coefficient of $\mathrm{CuO} /$ water nanofluids in a car radiator. Int. J. Therm. Sci. 66(2013), 66, 82-90.

[4] Peyghambarzadeh S.M., Hashemabadi S.H., Naraki M., Vermahmoudi Y.: Experimental study of overall heat transfer coefficient in the application of dilute nanofluids in the car radiator. Appl. Therm. Eng. 52(2013), 8-16.

[5] Wang X.Q., Mujumdar A.S.: Heat transfer characteristics of nanofluids. a review. Int. J. Therm. Sci. 46(2007), 1, 1-19.

[6] Eastman J.A., Choi U.S., Li S., Thompson L.J., Lee S.: Enhanced thermal conductivity through the development of nanofluids. Mater. Res. Soc. Symp. Proc., Cambridge Univ. Press (1997).

[7] Wang X., Xu X., Chor S.U.S.: Thermal conductivity of nanoparticle-fluid mixture. J. Thermophys. Heat Transfer 13(1999), 4, 474-480.

[8] Masuda H., Ebata A., Teramae K., Hishinuma N.: Alteration of thermal conductivity and viscosity of liquid by dispersing ultra-fine particles. Netsu Bussei 7(1993), 2, 227-233.

[9] Keshavarz M., Darabi M., Hossein Haddad S.M., Davarnejad R.: Modeling of convective heat transfer of a nanofluid in the developing region of tube flow with computational fluid dynamics. Int. Comm. Heat Mass Trans. 38(2011), 1291-1295. 
[10] Demir H., Dalkilic A.S., Kürekci N.A., Duangthongsuk W., Wongwises S.: Numerical investigation on the single phase forced convection heat transfer characteristics of $\mathrm{TiO}_{2}$ nanofluids in a double-tube counter flow heat exchanger. Int. Comm. Heat Mass Trans. 38(2011), 218-228.

[11] Das S.K., Putra N., Roetzel W.: Pool boiling characteristics of nano-fluids. Int. Comm. Heat Mass Transfer 46(2003), 851-862.

[12] Rajendran Senthilkumar Sethuramalingam Prabhu, Marimuthu CherALATHAN.: Experimental investigation on carbon nano tubes coated brass rectangular extended surfaces. Appl. Thermal Eng. 50(2013), 1361-1368.

[13] Singh Pawan K., Anoop K.B., Sundararajan T., Das Sarit K.: Entropy generation due to flow and heat transfer in nanofluids. Int. J. Heat Mass Trans. 53(2010), 21-22, 4757-4767.

[14] Drozynski Z.: Entropy increase as a measure of energy degradation in heat transfer. Arch. Thermodyn. 34(2013), 3, 147-160.

[15] Launder B.E., Spalding D.B.: Lectures in Mathematical Models of Turbulence. Academic Press, London 1972.

[16] Fluent-UG, Fluent Inc., FLUENT 6.3 User's Guide. NH, Lebanon 2006.

[17] Patankar S.V., Pratap V.S., Spalding D.B.: Prediction of turbulent flow in curved pipes. J. Fluid Mech. 67(1975), 583-595.

[18] PAK B.C., Сно Y.I.: Hydrodynamic and heat transfer study of dispersed fluids with submicron metallic oxide particles. Experimental Heat Transfer: J. Therm. Energ. Gener. Transp. Stor. Conver. 11(1998), 151-170.

[19] Koo J., Kleinstreuer C.: A new thermal conductivity model for nanofluids. J. Nanoparticle Res. 6(2004), 577-588.

[20] BATChelor G.K.: The effect of Brownian motion on the bulk stress in a suspension of spherical particles. J. Fluid Mech. 83(1977), 1, 97-117.

[21] Xuan Y., Roetzel W.: Conceptions of heat transfer correlation of nanofluids. Int. J. Heat Mass Trans. 43(2000), 3701-3707.

[22] Hamilton R.L., Crosser O.K.: Thermal Conductivity of Heterogeneous TwoComponent Systems. Ind. Eng. Chem. Fund. 3(1962), 187-191.

[23] Turgut A., Tavman I., Chirtoc M., Schuchmann H.P., C. Sauter, Tavman S.: Thermal conductivity and viscosity measurements of water based $\mathrm{TiO}_{2}$ nanoflu$i d s$. Int. J. Thermophys. 30(2009), 1213-1226.

[24] YU W., Chor S.U.S.: The role of interfacial layers in the enhanced thermal conductivity of nanofluids; a renovated Maxwell model. J. Nanoparticle Res. 5(2003), $167-171$.

[25] Bejan A.: A study of entropy generation in fundamental convective heat transfer. J. Heat Trans. ASME 101(1979), 718-725.

[26] Bejan A.: Entropy Generation through Heat and Fluid Flow. Willy \& Sons, 1982.

[27] Qasim Saleh Mahdi, Sahar A. Fattah, AbboodFiras A. Abbas.: Investigation of heat transfer from U-longitudinal finned tube heat exchanger. Adv. Energ. Power 3(2015), 19-28. 